\title{
MORTALITY AMONG PATIENTS WITH ACUTE ON TOP OF CHRONIC LIVER FAILURE IN ZAGAZIG UNIVERSITY HOSPIATALS.
}

\author{
Amr S. Ebrahim a, Afifi F. Afifi a, Ihab Barsoum ${ }^{\text {a }}$, Waseem M. Seleem a, Ayman M. \\ Marei b \\ a Internal Medicine Department, Faculty of Medicine, Zagazig University, Zagazig, Egypt. \\ ${ }^{\mathrm{b}}$ Medical Microbiology and Immunology Department, Faculty of Medicine, Zagazig University, \\ Zagazig, Egypt.
}

Corresponding Author

Dr Amr Samir Ebrahim, amrsamir500@yahoo.com

\begin{abstract}
Introduction: ACLF is acute deterioration of preexisting chronic liver disease usually related to a precipitating event characterized by the presence of organ failure and a very high risk of short-term mortality. We focused in this study on mortality outcome among ACLF patients which is more devastating than patients with mere acute decompensation. Several definitions have been developed by expert groups all over the world for better characterization of this group of patients; however there is no consensus on one definition. Aim of the study: to identify the characteristics of patients with ACLF and their mortality in Zagazig university hospitals. Patients and methods: we followed patients admitted to hepatology intensive care unit with acute hepatic decompensation, we included 30 patients of them as ACLF and they were managed with tight monitoring and close follow up till either discharge or death. Results: The present study proved that there was high mortality rate among ACLF patients in our study (19 out of 30 patients). Conclusion: ACLF carries a high mortality rate in comparison with patient's admitted with acute decompensation.
\end{abstract}

Keywords: ACLF, mortality, SOFA score, organ failure, acute decompensation

\section{INTRODUCTION}

P atients with cirrhosis may develop acute complications such as ascites, hepatic encephalopathy, gastro-intestinal hemorrhage and bacterial infections that lead to hospitalization. On admission, some of these patients will have mere decompensated cirrhosis, whereas others will exhibit decompensated cirrhosis associated with newly developed liver and/or extrahepatic organ failure. Those patients are considered to have $\operatorname{ACLF}^{(1)}$.

Acute on chronic liver failure is acute deterioration of preexisting chronic liver disease usually related to a precipitating event characterized by the presence of organ failure and a very high risk of short-term mortality ${ }^{(2)}$.

It is very important to distinguish between chronic decompensation resulting from progression of chronic liver disease, which in most cases is irreversible, and ACLF, which may be reversible if the trigger factor is treated. It is noteworthy that liver disease and a precipitating event are found in both ACLF and acute liver decompensation, and organ failure associated with high short-term mortality in ACLF is the only difference between these two conditions ${ }^{(2) .}$

The degree and number of organ failures are the major factors determining the outcome (mortality) of patients with ACLF, and not the degree of liver disease ${ }^{(3)}$.

\section{AIM OF THE WORK}

It is very important to distinguish between mortality outcomes among ACLF patients in contrast with patients with mere acute decompensation. So, we aim to identify the characteristics of patients with ACLF and their mortality in Zagazig university hospitals.

\section{SUBJECTS AND METHODS}

Comparative cross sectional study was carried out in hepatology unit, Internal 
Medicine Department, Faculty of Medicine, Zagazig University Hospitals between April 2017 and October 2017.

It included 60 cirrhotic patients admitted with acute hepatic decompensation, 30 patients diagnosed as ACLF according to EASL-CLIF definition (table 1) and (table 2), while the other group of patients were diagnosed as mere acute decompensation and not ACLF according to EASL-CLIF definition. Acute decompensation was defined by the acute development of large ascites, hepatic encephalopathy, gastrointestinal hemorrhage, bacterial infection, or any combination of these.

Table (1): GRADES OF ACLF ${ }^{(4)}$

\begin{tabular}{|c|c|c|c|c|}
\hline Grade & No ACLF & ACLF grade 1 & $\begin{array}{c}\text { ACLF } \\
\text { grade } 2\end{array}$ & $\begin{array}{c}\text { ACLF } \\
\text { grade } 3\end{array}$ \\
\hline Definition & $\begin{array}{l}\text { No organ failure } \\
\text { Or } \\
\text { Single organ failure } \\
\text { (coagulation, } \\
\text { circulation or } \\
\text { respiration) and } \\
\text { creatinemia }<1.5 \\
\mathrm{mg} / \mathrm{dl} \text { and no } \\
\text { hepatic } \\
\text { encephalopathy }\end{array}$ & $\begin{array}{l}\text { Single kidney failure } \\
\text { or Single organ } \\
\text { failure (coagulation, } \\
\text { circulation or } \\
\text { respiration) and } \\
\text { creatinemia between } \\
1.5 \text { and } 1.9 \mathrm{mg} / \mathrm{dl} \text { or } \\
\text { hepatic } \\
\text { encephalopathy and } \\
\text { creatinemia between } \\
1.5 \text { and } 1.9 \mathrm{mg} / \mathrm{dl}\end{array}$ & $\begin{array}{l}\text { Two organ } \\
\text { failures }\end{array}$ & $\begin{array}{l}\text { Three } \\
\text { organ } \\
\text { failures }\end{array}$ \\
\hline
\end{tabular}

Table (2): Chronic liver failure-sequential organ failure assessment score

\begin{tabular}{|c|c|c|c|c|c|}
\hline Organ & $\mathbf{0}$ & 1 & 2 & 3 & 4 \\
\hline $\begin{array}{l}\text { Liver } \\
\text { (Bilirubin, mg/dl) }\end{array}$ & $<1.2$ & $\geq 1.2-\leq 1.9$ & $\geq 2-\leq 5.9$ & $\geq 6-<12$ & $\geq 12$ \\
\hline \multirow{2}{*}{$\begin{array}{l}\text { Kidney (Creatinine } \\
(\mathrm{mg} / \mathrm{dl})\end{array}$} & \multirow[t]{2}{*}{$<1.2$} & \multirow{2}{*}{$\geq 1.2-\leq 1.9$} & $\geq 2-<3.5$ & $\geq 3.5-<5$ & $\geq 5$ \\
\hline & & & \multicolumn{3}{|c|}{ Or use of renal replacement therapy } \\
\hline $\begin{array}{l}\text { Cerebral } \\
\text { (HE grade) }\end{array}$ & No HE & 1 & 2 & 3 & 4 \\
\hline Coagulation (INR) & $<1.1$ & $\geq 1.1-<1.25$ & $\geq 1.25-<1.5$ & $\geq 1.5-<2.5$ & $\begin{array}{c}\geq 2.5 \text { or platelets } \\
\leq 20 \times 10^{9}\end{array}$ \\
\hline $\begin{array}{l}\text { Circulation } \\
(\mathrm{MAP} \mathrm{mm} \mathrm{Hg})\end{array}$ & $\geq 70$ & $<70$ & $\begin{array}{c}\text { Dopamine } \leq 5 \text { or } \\
\text { dobutamine or } \\
\text { Terlipressin }\end{array}$ & $\begin{array}{c}\text { Dopamine }>5 \text { or } \\
\text { epinephrine } \leq 0.1 \\
\text { or norepinephrine } \\
\leq 0.1\end{array}$ & $\begin{array}{l}\text { Dopamine }>15 \text { or } \\
\text { epinephrine }>0.1 \text { or } \\
\text { norepinephrine }>0.1\end{array}$ \\
\hline $\begin{array}{l}\text { Lungs } \\
\text { PaO/Fio2: } \\
\text { Or Spo2/Fio2 }\end{array}$ & $\begin{array}{l}>400 \\
>512\end{array}$ & $\begin{array}{l}>300-\leq 400 \\
>357-\leq 512\end{array}$ & $\begin{array}{l}>200-\leq 300 \\
>214-\leq 357\end{array}$ & $\begin{array}{c}>100-\leq 200 \\
>8-\leq 214\end{array}$ & $\begin{array}{l}\leq 100 \\
\leq 89\end{array}$ \\
\hline
\end{tabular}

The shaded text indicates the diagnostic criteria for organ failure. HE: Hepatic Encephalopathy; INR: International normalized ratio; $\mathrm{PaO}_{2}$ : Partial pressure of arterial oxygen; $\mathrm{FiO}_{2}$ : Fraction of inspired oxygen; $\mathrm{SpO}_{2}$ : Pulse oximetry saturation. Data from Moreau and colleagues ${ }^{(2)}$

\section{Inclusion Criteria:}

Age: > 18 years and of either sex, cirrhotic patient (whatever the etiology) either ACLF or mere acute decompensation.

\section{Exclusion Criteria:}

We have excluded patients with age less than 18 years old, patients with acute or subacute liver failure, cirrhotic patients who develop decompensation following partial hepatectomy or TACE, patients with severe extra hepatic diseases, pregnant patients, patients receiving immunosuppressive drugs, Hepatocellular carcinoma outside Milan criteria, HIV infection, diseases affecting serum copeptin level e.g. acute myocardial infarction, heart failure, cerebral hemorrhage, poly cystic kidney.

\section{Ethical clearance:}




\section{Amr et al.}

Written Informed consent was taken from the patients' relatives to participate in the study. Approval for performing the study was obtained from Institutional Review Board (IRB) approval.

\section{Operational design:}

\section{All patients were subjected to:}

1. Detailed history taking with stress on recent drugs, herbal remedies, alcohol or recent interventions or operations.

2. Thorough clinical examination: taking in consideration symptoms and signs of acute hepatic decompensation and other organ affection (e.g. C.N.S, respiratory, cardiac or renal failure).

3. Investigations including:

- Routine laboratory investigations (complete blood count, liver function tests, kidney function tests and prothrompin time), $\mathrm{ABG}$, serum electrolytes e.g. serum $\mathrm{Na}^{+}, \mathrm{K}^{+}, \mathrm{Ca}^{++}$\& $\mathrm{Mg}^{++}$level, screening for infections including culture of blood, urine, and ascitic fluid, as required according to the clinical suspicion \& follow up of the patients.
Zagazig University Medical Journals

- Pelvi-abdominal ultrasound, electrocardiography and echocardioraphy when appropriate.

Assessment of organ failure using CLIFSOFA score (table 2)

STATISTICAL ANALYSIS

All data were collected, tabulated and statistically analyzed using SPSS 20.0 for windows (SPSS Inc., Chicago, IL, USA). Quantitative data were expressed as the mean \pm SD \& median (range), and qualitative data were expressed as \& (percentage).

Independent samples Student's t-test was used to compare between two groups of normally distributed variables while Mann Whitney $U$ test was used for non- normally distributed variables. F-test was used to compare between more than two groups of normally distributed while Kruskall Wallis test was used for non- normally distributed variables. Percent of categorical variables were compared using Chi-square test. All tests were two sided. P-value $<0.05$ was considered statistically significant $(\mathrm{S})$, and $\mathrm{p}$-value $\geq 0.05$ was considered statistically insignificant (NS).

\section{RESULTS}

Table (3): Laboratory finding of studied groups

\begin{tabular}{|c|c|c|c|c|}
\hline & ACLF patients & $\begin{array}{c}\text { Patients with } \\
\text { acute decompensation }\end{array}$ & \multirow[t]{2}{*}{$* P$} & \multirow[t]{2}{*}{ Sig. } \\
\hline & Median (range) & Median (range) & & \\
\hline WBCs $\left(4--11 \times 10^{3} / \mathrm{cm}\right)$ & $10.5(1.8-67)$ & $9.6(2-23.6)$ & 0.41 & NS \\
\hline Hemoglobin (12--18 g/dl) & $9.2(6-12)$ & $9.1(5-13)$ & 0.65 & NS \\
\hline Platelet $\left(150--400 \times 10^{3} / \mathrm{cm}\right.$ & $136(36-400)$ & $98(30-488)$ & 0.34 & NS \\
\hline INR & $1.75(1.3-3.5)$ & $1.5(1.2-2.7)$ & 0.014 & $\mathrm{~S}$ \\
\hline Serum ALT $(n=30-65 \mu / L)$ & $36.5(7-248)$ & $34(10-108)$ & 0.94 & NS \\
\hline Serum AST $(n 15-37=\mu / L)$ & $54(11-520)$ & $53(12-222)$ & 0.74 & NS \\
\hline Total bilirubin & $4.5(.3-26)$ & $2.1(.3-18)$ & 0.004 & $\mathrm{~S}$ \\
\hline Albumin & $2.5(1.3-3.4)$ & $2.7(1.3-4)$ & 0.07 & NS \\
\hline Serum creatinine $:(0.5-1.4 \mathrm{mg} / \mathrm{dl})$ & $2.45(0.8-10)$ & $1.1(0.49-2.1)$ & $\begin{array}{c}0.000 \\
1\end{array}$ & HS \\
\hline $\mathrm{Na}$ & $130.5(118-190)$ & $129.5(118-141)$ & 0.21 & NS \\
\hline Potassium & $4.5(2.4-7.1)$ & $2.8(1.5-3.5)$ & $\begin{array}{c}0.000 \\
1\end{array}$ & $\mathrm{HS}$ \\
\hline
\end{tabular}

*Mann Whitney test

There is highly statistical significant difference between the 3 group as regard WBCs, Hb, albumin and total bilirubin, BUN, serum creatinine, total proteins and $\mathrm{K}^{+}$ 
Table (4): Precipitating events for ACLF patients

\begin{tabular}{|l|c|c|}
\hline \multicolumn{1}{|c|}{ Precipitated event of ACLF } & \multicolumn{2}{|c|}{ ACLF patients (N=30) } \\
\cline { 2 - 3 } & No. & \% \\
\hline Unknown precipitating event & 13 & 43.3 \\
\hline Infections & 11 & 36.66 \\
$\bullet \quad$ SBP & 6 & 20 \\
$\bullet \quad$ Pneumonia & 3 & 10 \\
$\bullet \quad$ UTI & 2 & 6.66 \\
\hline Hematemesis & 4 & 13.3 \\
\hline Post -operative & 2 & 6.66 \\
\hline
\end{tabular}

The table shows that $43 \%$ of ACLF patients were with unknown precipitating event and about $36 \%$ of patients were precipitated by infections including spontaneous bacterial peritonitis, pneumonia and urinary tract infection. Hematemesis and post operative sequale were the precepiting factors in about $13 \%$ and $7 \%$ respectively.

Table (5): Culture and sensitivity of ascetic fluid among ACLF patients

\begin{tabular}{|l|l|c|c|}
\hline \multicolumn{2}{|c|}{ Microbiology } & \multicolumn{2}{c|}{ ACLF patients (N=30) } \\
\hline \multicolumn{1}{|c|}{ Organism } & Antibiotic sensetivity & No. & \% \\
\hline No & & 22 & 73.8 \\
\hline pseudomonas auregenosa & Meropenem & 4 & 13 \\
\hline Enterococci & Tigacycline & 1 & 3.3 \\
\hline E choli & Levofloxacin & 1 & 3.3 \\
\hline E choli & Ceftriaxone & 1 & 3.3 \\
\hline pseudomonas auregenosa & Tinam & 1 & 3.3 \\
\hline
\end{tabular}

This table showed that pseudomonas auregonosa $(16.3 \%)$ was the most frequently encountered organism in the ascetic fluid followed by E choli (6.6\%) and enterococci (3.3\%).

Table (6): Organ failure among ACLF patients.

\begin{tabular}{|l|c|c|}
\hline \multicolumn{1}{|c|}{ Organ failure } & \multicolumn{2}{c|}{$\begin{array}{c}\text { ACL patients } \\
\text { (N=30) }\end{array}$} \\
\cline { 2 - 3 } & No. & \% \\
\hline One organ failure & & 33.3 \\
\hline Renal & 10 & 6.6 \\
\hline Coagulopathy & 2 & 10 \\
\hline Cerebral & 3 & \\
\hline Two organ failure & & 13.3 \\
\hline Liver and renal & 4 & 6.6 \\
\hline Liver and coagulopathy & 2 & 6.6 \\
\hline Liver and cerebral & 2 & 17 \\
\hline Renal and cerebral & 5 & \\
\hline Three organs failure & & 6.6 \\
\hline Liver, coagulopathy and cerebral & 2 & \\
\hline
\end{tabular}

The table shows that $50 \%$ of ACLF patients had one organ failure, renal (33.3\%), cerebral (10\%) and coagulopathy $(6.6 \%) .13$ patients had two organ failure and only two patients had three organs failure. 
Table (7): Mortality among the studied groups.

\begin{tabular}{|c|c|c|c|c|c|c|}
\hline \multirow[t]{2}{*}{ Mortality } & \multicolumn{2}{|c|}{$\begin{array}{l}\text { ACLF patients } \\
(\mathbf{N}=\mathbf{3 0})\end{array}$} & \multicolumn{2}{|c|}{$\begin{array}{l}\text { Patients with acute } \\
\text { decompensation } \\
(\mathrm{N}=30)\end{array}$} & \multirow[t]{2}{*}{$\chi^{2}$} & \multirow[t]{2}{*}{ p-value } \\
\hline & No. & $\%$ & No. & $\%$ & & \\
\hline $\begin{array}{l}\text { Survived } \\
\text { Died }\end{array}$ & $\begin{array}{l}11 \\
19\end{array}$ & $\begin{array}{l}36.7 \\
63.3\end{array}$ & $\begin{array}{c}25 \\
5\end{array}$ & $\begin{array}{l}83.4 \\
16.6\end{array}$ & 13.6 & $\begin{array}{c}0.0002 \\
\text { (HS) }\end{array}$ \\
\hline
\end{tabular}

This table shows that there is a high statistically significant difference as regard mortality between ACLF patients and patients with acute decompensation.

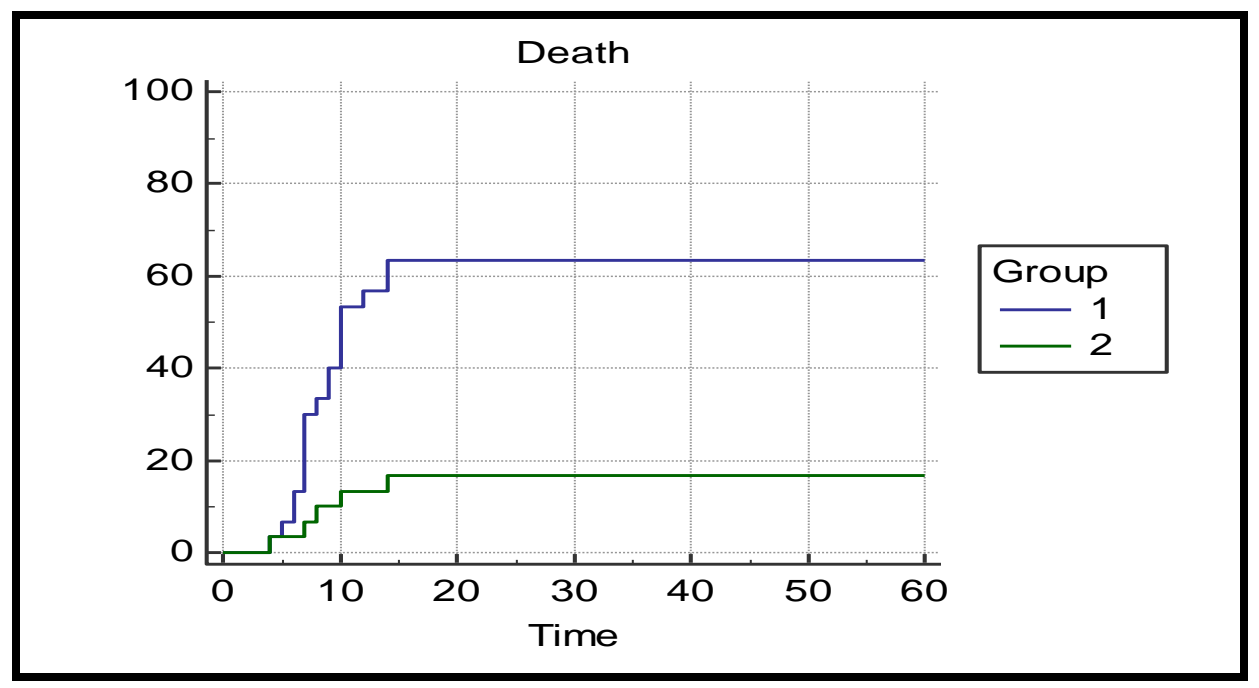

Figure (1): Kaplanmeier curve showing mortality among the studied groups.

Table (8): Mortality among patients with ACLF according to the presence or absence of precipitating events

\begin{tabular}{|l|c|c|c|}
\hline \multirow{2}{*}{ ACLF } & Mortality(19) & Survival(11) & \multirow{2}{*}{ *p } \\
\cline { 2 - 3 } Precipitating events & No (\%) & No (\%) & \\
\hline Known precipitating events (17) & $13(68)$ & $4(36)$ & 0.13 \\
Unknown precipitating events (13) & $6(32)$ & $7(64)$ & $(\mathrm{NS})$ \\
\hline
\end{tabular}

*Fisher exact test

This table shows that there is no statistical significant difference as regard the mortality among ACLF patients with known or unknown precipitating events.

Table (9): Mortality among patients with acute decompensation according to the presence or absence of precipitating events

\begin{tabular}{|l|c|c|c|}
\hline \multirow{2}{*}{ Acute decompensation } & Mortality(5) & Survival(25) & \multirow{2}{*}{$* \mathbf{p}$} \\
\cline { 2 - 3 } Precipitating events & No (\%) & No (\%) & \\
\hline Known precipitating factor(20) & $3(60)$ & $17(68)$ & 0.9 \\
Unknown precipitating factor(10) & $2(40)$ & $8(32)$ & \\
\hline
\end{tabular}

*Fisher exact test

This table shows that there is no statistical significant difference as regard the mortality among patients with acute decompensation with known or unknown precipitating events. 
Table (10): Relation between survival of ACLF patients and different study parameters.

\begin{tabular}{|c|c|c|c|c|}
\hline \multirow{2}{*}{$\begin{array}{l}\text { Survival } \\
\text { Variables }\end{array}$} & Mortality(19) & Survival(11) & \multirow[t]{2}{*}{ (p) } & \multirow[t]{2}{*}{ significance } \\
\hline & Median (range) & Median (range) & & \\
\hline Age & $57.6 \pm 8.4$ & $58 \pm 8.2$ & T test 0.9 & \\
\hline MAP & $68(55-70)$ & $70(66-78)$ & $* 0.28$ & \\
\hline ALT & $37(7-148)$ & $20(9-248)$ & $* 0.47$ & \\
\hline AST & $63(21-323)$ & $48(11-520)$ & $* 0.49$ & \\
\hline Total bilirubin & $6(0.9-25)$ & $2.9(0.3-26)$ & $* 0.018$ & $\mathrm{~S}$ \\
\hline $\begin{array}{l}\text { Total protein Mean } \\
\pm \text { SD }\end{array}$ & $5.8 \pm 0.67$ & $5.9 \pm 0.97$ & T test 0.7 & \\
\hline Albumin (Mean \pm SD) & $2.3 \pm .4$ & $2.6 \pm 0.48$ & T test 0.07 & \\
\hline Urea & $112(19-280)$ & $140(2-280)$ & $* 0.76$ & \\
\hline Creatinin & $2.5(0.8-10)$ & $2.4(0.9-5.1)$ & $* 0.6$ & \\
\hline $\mathbf{N a}$ & $112(19-280$ & $140(2-280)$ & $* 0.9$ & \\
\hline Potassium Mean \pm SD & $4.5 \pm 1.1$ & $4.6 \pm 1$ & T test 0.8 & \\
\hline WBCs & $10.4(1.8-67)$ & $10.7(2-25)$ & $* 0.8$ & \\
\hline PLT & $98(36-275)$ & $143(45-400)$ & $* 0.3$ & \\
\hline INR & $1.9(1.34-2.8)$ & $1.6(1.3-3.5)$ & $* 0.036$ & $S$ \\
\hline Copeptin pmol/ml & $\begin{array}{c}448.9(257- \\
773.09)\end{array}$ & $\begin{array}{c}407.2(154.6- \\
738.67)\end{array}$ & $* 0.78$ & \\
\hline CTP & $12(6-14)$ & $10(7-12)$ & $* 0.003$ & $\mathrm{~S}$ \\
\hline SOFA score & $10(6-13)$ & $9(5-11)$ & $* 0.01$ & $S$ \\
\hline Meld score & $30 \pm 5$ & $25 \pm 6$ & $* * 0.01(\mathrm{~S})$ & \\
\hline Organ failure & no $(\%)$ & no $(\%)$ & & \\
\hline $\begin{array}{l}\text { One } \\
\text { Two } \\
\text { Three }\end{array}$ & $\begin{array}{c}8(42) \\
10(53) \\
1(5)\end{array}$ & $\begin{array}{c}7(64) \\
4(36) \\
0\end{array}$ & ${ }^{\#} 0.4$ & \\
\hline
\end{tabular}

*Mann-Whitnney $\quad * *$ t test $\quad$ chi square test \#0.4

This table shows that there is statistically significant relation between INR,CTP ,SOFA score, total bilirubin, MELD score and survival of ACLF patients $\mathrm{p}<0.05$

Table (11): Validity of variables to predict mortality of ACLF patients

\begin{tabular}{|l|c|c|c|c|c|c|c|c|}
\hline \multicolumn{1}{|c|}{ Variables } & AUC & $\begin{array}{c}\mathbf{9 5 \%} \\
\text { CI }\end{array}$ & $\begin{array}{c}\mathbf{P} \\
\text { value }\end{array}$ & $\begin{array}{c}\text { Optimal } \\
\text { cut off }\end{array}$ & $\begin{array}{c}\text { Sensitivity } \\
\%\end{array}$ & $\begin{array}{c}\text { Specificity } \\
\%\end{array}$ & PPV\% & NPV\% \\
\hline SOFA score & $\mathbf{0 . 7 7}$ & $0.6-.94$ & 0.01 & 10 & 79 & 73 & 83 & 67 \\
\hline CTP score & $\mathbf{0 . 8 2}$ & $0.67-.97$ & 0.004 & 12 & 63 & 91 & 92 & 59 \\
\hline $\begin{array}{l}\text { Total bilirubin } \\
\text { Mg/dL }\end{array}$ & $\mathbf{0 . 7 6}$ & $0.56-0.96$ & 0.02 & 3.1 & 89 & 64 & 81 & 78 \\
\hline INR & $\mathbf{0 . 7 3}$ & $0.5-.93$ & 0.037 & 1.75 & 68 & 82 & 87 & 60 \\
\hline MELD score & $\mathbf{0 . 7 5}$ & $0.57-.95$ & 0.019 & 29 & 63 & 82 & 86 & 65 \\
\hline
\end{tabular}

AUC: area under curve, $\mathrm{CI}=$ confidence interval $\mathrm{PPV}=$ positive predictive value, $\mathrm{NPV}=$ negative predictive value

DISCUSSION

Our study included 60 cirrhotic patients which were divided into 2 groups:

Group I: it included 30 cirrhotic patients diagnosed as ACLF, they were 15 males and 15 females. Their age ranged from 41 to 73 with mean age \pm SD was $56.6 \pm 8.4$.

Group II: included 30 cirrhotic patients presented with acute decompensation and not ACLF, they were15 males and 15 females. 


\section{Amr et al.}

Their age ranged from 42 to 75 with mean age \pm SD was $56.9 \pm 8$.

$\mathrm{HCV}$ was the most frequent underlying etiology for chronic liver disease in the three groups. $\mathrm{HCV}$ is the most prevalent hepatic viral infection in Egypt. An Egyptian demographic health survey conducted in 2008 concluded that $14.7 \%$ of the population have been infected, making this the highest prevalence in any population in the world ${ }^{(5)}$. Reduction in the overall prevalence of $\mathrm{HCV}$ antibody from 14.7 to $10.0 \%$ between 2008 and 2015 among those aged 15-59 years ${ }^{(6)}$. Other studies showed that alcohol was the most common cause of chronic liver diseases as Gupta et al., 2016 showed that the most common aetiology of underlying chronic liver disease was alcohol (79.16\%). HBV, NASH and cryptogenic cause constitutes $8.33,9.16$ and $3.33 \%$ respectively ${ }^{(7)}$ and Moreau et al., 2013 found that alcohol was the most common cause of cirrhosis in about $60 \%$ of patients in ACLF group and $49 \%$ in non ACLF group ${ }^{(2) .}$

In our study the precipitating event for development of ACLF was unknown in $43 \%$ of ACLF patients and about $36 \%$ of patients were precipitated by infections including spontaneous bacterial peritonitis, pneumonia and urinary tract infection. Hematemesis and post operative sequale (strangulated umbilical hernia) were the precipitating factors in about $13 \%$ and $7 \%$ respectively. This was consistent with Moreau et al., 2013 who reported that no precipitating event was identifiable in $43.6 \%$ of patients with $\operatorname{ACLF}^{(2)}$. Gupta et al., 2016 showed that the most common acute insult was alcoholic hepatitis $(49.16 \%)^{(7)}$. While the study conducted by Duseja et al., 2010 which included 102 patients with ACLF, reported that infection was the most common precipitating factor observed in those patients ${ }^{(8)}$.

Our study showed that there is no statistical significant difference as regard the mortality among ACLF patients with known or unknown precipitating events. This was consistent with Moreau et al., 2013 who reported that the presence or absence or the type of precipitating event was unrelated to the severity of ACLF and 28-day mortality rate ${ }^{\text {(2). }}$

\section{Zagazig University Medical Journals}

As regard organ failure, our study showed that $50 \%$ of ACLF patients were ACLF grade 1 (15 patients) while ACLF grade 2 and ACLF grade 3 were $43.4 \%$ (13 patients) and $6.6 \%$ (two patients) respectively. Also we found that renal failure was the most prevalent organ failure in ACLF patients with frequency of $66.6 \%$ either alone or in association with other organ damage e.g. liver failure, coagulopathy and HE. Also we recorded that liver failure occurred in about $33.3 \%$ of ACLF patients.

This was matching with Moreau et al., 2013 who reported that renal failure was the most prevalent organ failure for ACLF grade 1 while liver failure was the most prevalent organ failure in ACLF grade 2, followed by kidney, cerebral, and coagulation failures. Regarding ACLF grade 3, the prevalence of all organ failures was high ${ }^{\text {(2). }}$ Also Gupta et al., 2016 showed that the most common organ failure was liver failure in $34.66 \%$ of patients followed by coagulopathy in $18.6 \%$. Other organs failure such as kidney, cerebral, circulatory and respiratory failures were found in $16.8,15.11,8.88$ and $5.7 \%$ respectively. Also the presence of $1,2, \geq 3$ organ failure was found in $18.33 \%, 23.33 \%$ and $32.5 \%$ of patients respectively ${ }^{(7) \text {. }}$

As regard the outcome of ACLF patients, in our study, mortality of patients with ACLF grade 1 , grade 2 and grade 3 was $53.3 \%, 69.2$ $\%$ and $100 \%$ respectively. $40 \%$ of ACLF patients died within 10 days from admission. 28-day mortality rate was $100 \%$. Our results are near to the experience of INASL (Indian National Association for the Study of Liver) consortium 2016 who found that $42.6 \%$ (447/1049) patients died during a median hospital stay of 8 days ${ }^{(9) .}$

Moreau et al., 2013 showed that 28-day and 90-day mortality rates of ACLF grade1were $22.1 \%$ and $40.7 \%$, respectively, 28-day and 90-day mortality rates of ACLF grade 2 were $32.0 \%$ and $52.3 \%$, respectively and 28-day and 90-day mortality rates of ACLF grade 3 were $76.7 \%$ and $79.1 \%$, respectively (2). While Gupta et al., 2016 showed that 7 days, 14 days and 28 days mortality was $29 \%, 41 \%$ and $44 \%$ respectively (7). Our rates of mortality were higher and this may be attributed to many factors which include delay in culture results, lack of 


\section{Amr et al.}

artificial artificial liver support devices as they were expensive and considered as a bridge to liver transplantation and small number of ACLF patients in our study (30 patients). Also liver transplantation facilities weren't present in our hospital.

Our study showed that there is a high statistically significant difference as regard mortality between ACLF patients $(63.3 \%)$ (19 out of 30 patients) and patients with acute decompensation $(16.6 \%)$ (5 out of 30 patients). Moreau et al., 2013 showed that 28day and 90-day mortality rates in patients with ACLF were $32.8 \%$ (136 out of 415)and 51.2\% (212 out of 415) respectively. ACLF is associated with a short-term mortality rate 15 times higher than that in patients with acute decompensation alone (2). Gupta et al., 2016 found that 28 days mortality among ACLF patients was $43.3 \%$ (52 out of 120 patients) ${ }^{(7) .}$ The difference between our results and that done by Moreau et al., 2013 may be related to small number of patients included in the study also patients in the other study were enlisted for liver transplantation.

In comparison with other markers SOFA score, CTP, total bilirubin and MELD score were considered as independent predictors of mortality. This was consistent with Gupta et al., 2016 who showed that the prognosis was worst in patients who had high bilirubin, high MELD and SOFA scores ${ }^{(7) .}$

\section{CONCLUSION}

In conclusion, ACLF is characterized by distinctive clinical features being more dangerous in the terms of mortality; awareness among physicians as regard this new entity should be highlighted. Few data are available about the etiology and outcome of this condition in Egypt. Total bilirubin, serum creatinine and INR all contribute significantly with the prognosis of ACLF patients. ACLF is associated with a short-term mortality rate higher than that in patients with acute

\section{Zagazig University Medical Journals}

decompensation alone. ACLF patients should be transferred to centre with liver transplantation facilities once diagnosis of ACLF is settled. It should be of note that, further evaluation and validation of new and relevant biomarkers will facilitate newer more comprehensive scores which, either alone or in combination with existing scoring systems can predict the outcome of those group of patients.

\section{REFERENCES}

1- Malik R, Mookerjee RP, Jalan R.: Infection and inflammation in liver failure: two sides of the same coin. J Hepatol; 2009; 51(3): 426-429.

2- Moreau R, Jalan R, Gines P, et al.: Acute-onchronic liver failure is a distinct syndrome that develops in patients with acute decompensation of cirrhosis. Gastroenterology; 2013; 144: 14261437.

3- Jalan R, Gines P, Olson JC, et al.: Acute-onchronic liver failure. J Hepatol. 2012; 57:13361348.

4- Amathieu R and Al-Khafaji R: Definitions of acute-on-chronic liver failure: the past, the present, and the future. EMJ Hepatol; 2015; $3[1]: 35-40$.

5- El-Zanaty $\mathbf{F}$ and Way A.: Egypt Demographic and Health Survey 2008. Cairo, Egypt: Ministry of Health,ElZanaty and Associates, and Macro International.

6- Kandeel A, Genedy M, El-Refai S, et al.: The prevalence of HCV infection in Egypt 2015: implications for future policy on prevention and treatment. Liver Int.; 2017; 37:45-53.

7- Gupta M, Dadhich S, Bhargawa N, et al.: Clinical Profile of Patients with AcuteonChronic Liver Failure. J Gastroenterol Liver Dis. 2016; 1(1): 1007.

8- Duseja A, Chawla Y, Dhiman R, et al.: Nonhepatic insults are common acute precipitants in patients with acute on chronic liver failure (ACLF). Dig Dis Sci.; 2010; 55:3188-3192.

9- Shalimar, Saraswat V, Singh SP, et al.: Acute on chronic liver failure in India: the INASL consortium experience. J Gastroenterol Hepatol. ; 2016; 31: 1742-174 